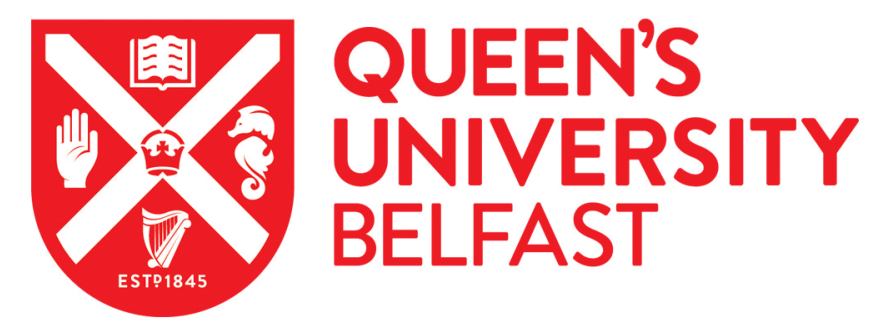

\title{
The Northern Ireland Public Access Defibrillation (NIPAD) study: effectiveness in urban and rural populations
}

Moore, M., Hamiliton, A. J., Cairns, K., Marshall, A., Glover, B. M., McCann, J., Jordan, J., Kee, F., \& Adgey, A. J. (2008). The Northern Ireland Public Access Defibrillation (NIPAD) study: effectiveness in urban and rural populations. Heart, 94(12), 1614-1619. https://doi.org/10.1136/hrt.2007.130534

Published in:

Heart

Queen's University Belfast - Research Portal:

Link to publication record in Queen's University Belfast Research Portal

\section{General rights}

Copyright for the publications made accessible via the Queen's University Belfast Research Portal is retained by the author(s) and / or other copyright owners and it is a condition of accessing these publications that users recognise and abide by the legal requirements associated with these rights.

Take down policy

The Research Portal is Queen's institutional repository that provides access to Queen's research output. Every effort has been made to ensure that content in the Research Portal does not infringe any person's rights, or applicable UK laws. If you discover content in the Research Portal that you believe breaches copyright or violates any law, please contact openaccess@qub.ac.uk. 


\section{The Northern Ireland Public Access Defibrillation (NIPAD) study: effectiveness in urban and rural populations}

M J Moore, A J Hamilton, K J Cairns, A Marshall, B M Glover, C J McCann, J Jordan, F Kee and A A J Adgey

Heart 2008;94;1614-1619; originally published online 29 Jan 2008; doi:10.1136/hrt.2007.130534

Updated information and services can be found at:

http://heart.bmj.com/cgi/content/full/94/12/1614

\section{These include:}

References This article cites 26 articles, 11 of which can be accessed free at: http://heart.bmj.com/cgi/content/full/94/12/1614\#BIBL

Rapid responses You can respond to this article at:

http://heart.bmj.com/cgi/eletter-submit/94/12/1614

Email alerting Receive free email alerts when new articles cite this article - sign up in the box at service the top right corner of the article

Topic collections Articles on similar topics can be found in the following collections

Drugs: cardiovascular system (4829 articles)

Interventional cardiology (1654 articles)

Notes

To order reprints of this article go to:

http://journals.bmj.com/cgi/reprintform

To subscribe to Heart go to:

http://journals.bmj.com/subscriptions/ 


\title{
The Northern Ireland Public Access Defibrillation (NIPAD) study: effectiveness in urban and rural populations
}

\author{
M J Moore, ${ }^{1}$ A J Hamilton, ${ }^{1,2} \mathrm{~K}$ J Cairns, ${ }^{3}$ A Marshall, ${ }^{3}$ B M Glover, ${ }^{1}$ C J McCann, \\ J Jordan, ${ }^{4} \mathrm{~F} \mathrm{Kee}^{2}{ }^{2} \mathrm{~A}$ A J Adgey ${ }^{1}$
}

${ }^{1}$ Regional Medical Cardiology Centre, Royal Victoria Hospital, Belfast, Northern Ireland; ${ }^{2}$ Epidemiology and Public Health, Queen's University Belfast, Northern Ireland;

${ }^{3}$ Department of Applied Mathematics, Queen's University, Belfast, Northern Ireland; ${ }^{4}$ School of Nursing and Midwifery, Queen's University, Belfast, Northern Ireland

Correspondence to: Professor A A J Adgey, Regional Medical Cardiology Centre Grosvenor Road, Royal Victoria Hospital, Belfast BT12 6BA,

Northern Ireland; Jennifer. adgey@belfasttrust.hscni.net

Accepted 8 January 2008 Published Online First 29 January 2008

\begin{abstract}
Objective: To assess the impact of mobile automated external defibrillators (AEDs) on out-of-hospital cardiac arrests (OHCAs) in urban and rural populations.

Design: Prospective before and after intervention, population study.

Setting: Urban and rural areas of 160000 each. Patients, interventions and main outcome measures: In 2004-6 the demographics of OHCAs were assessed. In 2005-6 AEDs were deployed (29 urban, 53 rural): 335 urban first responders (FRs) and 493 rural FRs were trained in AED use and dispatched to OHCAs. Callto-response interval (CRI), resuscitation and survival-todischarge rates for OHCA were compared.
\end{abstract}

Results: In 2004 there were 163 urban OHCAs and the emergency medical services (EMS) attended 158 (ventricular fibrillation (VF) 27/158 (17.1\%)). In 2005-6 there were 226 OHCAs, EMS attended 216 (VF 30/216 $(13.9 \%))$. In 2005-6 FRs were paged to 128 OHCAs (56.6\%), FRs attended 88/128 (68.8\%): 18/128 (14.1\%) reached before the EMS. The best combined FR/EMS mean (SD) CRI in 2005-6 (5 min $56 \mathrm{~s}$ (4)) was better than the EMS alone in 2004 (7 $\mathrm{min}(3) ; p=0.002)$. Survival rate was $5.1 \%$ in $2004,1.4 \%$ in $2005-6$ ( $p=N S)$. In 2004 there were 131 rural OHCAs, EMS attended 121 (VF 19/121 (15.7\%)). In 2005-6 there were 122 OHCAs, EMS attended 114 (VF 19/114 (16.7\%)). In 2005-6 FRs were paged to 49 OHCAs, FRs attended 42/ 49 (85.7\%): $23 / 49$ (46.9\%) reached before the EMS. The best combined FR/EMS mean (SD) CRI in 2005-6 (9 min $22 \mathrm{~s}(6))$ was better than the EMS alone in 2004 (11 min $2 \mathrm{~s}(6) ; p=0.018)$. Survival rate was $2.5 \%$ in $2004,3.5 \%$ in 2005-6 ( $p=N S)$.

Conclusions: Despite improvement in CRI there was no impact on survival (witnessed arrest 32.8\%, VF 15.6\%).

Trial registration number: ISRCTN07286796.

Seventy-four per cent of fatal coronary artery disease (CAD) events in the United Kingdom occur outside hospital ${ }^{1}$ but $<20 \%$ occur in public places. ${ }^{2}$ A cumulative meta-analysis of the outcomes from out-of-hospital cardiac arrests (OHCAs) for defibrillator-capable emergency medical services (EMS) systems, reported a mean survival to discharge rate of only $7.4 \%{ }^{3}$ OHCA thus represents a major public health problem, ${ }^{2}$ but prehospital care has the greatest potential to have an impact on mortality from acute coronary events. ${ }^{1}$

Observations from a Seattle cardiac rehabilitation programme showed that the survival rate for ventricular fibrillation (VF) was almost $100 \%$ if patients were defibrillated immediately after sudden collapse. After delays of $10 \mathrm{~min}$ or longer, $95 \%$ of subjects die. ${ }^{4}$ However, according to the standards established by the United Kingdom Department of Health, paramedic services are required to reach $75 \%$ of OHCAs within 8 min. ${ }^{5} 6$

Over the past two decades, community-based strategies focusing on early defibrillation have emerged, most recently employing automated external defibrillators (AEDs). ${ }^{4}$ The goal of the American Heart Association Task Force on AEDs is widespread deployment, with the aim of increased lay participation. ${ }^{\text {? }}$

The objective of this study was to conduct an observational study with evaluation of public access defibrillation (PAD) in urban and rural communities in Northern Ireland.

\section{METHODS}

Year 1, 2004 (1 January to 31 December 2004), involved the prospective collection of data for OHCAs with a cardiac aetiology in the study areas. The incidence of OHCAs was calculated for two populations: an urban population in North and West Belfast, (estimated population 160 000) and a rural population in Antrim, Ballymena and Magherafelt local government districts, (the "Northern Neighbourhoods"; estimated population 160 000). Monitoring of OHCA incidence was performed prospectively by manual and electronic searches of EMS patient report forms and autopsy reports. This method has been shown to be more accurate than retrospective analysis of death certification data. ${ }^{28}$ We excluded all arrests with an obvious "non-cardiac" aetiology."

Throughout year 1 we also recruited and trained lay and police volunteers in AED use in each area. Recruitment of first responder (FR) volunteers started at the beginning of year 1 and continued throughout year 2. Various recruitment methods were used, including mail shots, a media campaign, a dedicated website and presentations to community groups. The Police Service of Northern Ireland Operational Policy Department facilitated the recruitment of police officers. About $60 \%$ of the volunteers had up-to-date cardiopulmonary resuscitation (CPR) training Training was based on the resuscitation guidelines in $2000^{10}$ for the use of AEDs. The instructortrainee ratio was generally 1:6. After an AED demonstration, each volunteer was given a simulated situation and assessed by the instructor. Retraining occurred at 6 months. Volunteer skills were rated on the basis of a simulated AED 
Table 1 Demographics for out-of-hospital cardiac arrest (OHCA) years 2004 and 2005-6 for the urban and rural areas

\begin{tabular}{|c|c|c|c|c|c|}
\hline & NWB 2004 & NWB 2005-6 & NN 2004 & NN 2005-6 & Total \\
\hline Number of $\mathrm{OHCAs}$ & 163 & 226 & 131 & 122 & 642 \\
\hline Number of weeks & 52 & 63 & 52 & 52 & - \\
\hline \multicolumn{6}{|l|}{ Gender } \\
\hline Male (\%) & $104(63.8)$ & $143(63.3)$ & $80(61.1)$ & 87 (71.3) & $414(64.5)$ \\
\hline Female (\%) & $59(36.2)$ & $83(36.7)$ & $51(38.9)$ & $35(28.7)$ & $228(35.5)$ \\
\hline \multicolumn{6}{|l|}{ Age } \\
\hline Mean (SD) & $67.1(13.9)$ & $66.0(15.4)$ & $70.2(14.4)$ & $70.2(16.3)$ & $67.9(15.1)$ \\
\hline Median (range) & $72(32-93)$ & $69(15-93)$ & $73(21-97)$ & $74(28-105)$ & $71(15-105)$ \\
\hline \multicolumn{6}{|l|}{ Site } \\
\hline Home (\%) & $145(89.0)$ & $191(84.5)$ & $104(79.4)$ & $94(77.0)$ & $534(83.2)$ \\
\hline Public place (\%) & $12(7.4)$ & $15(6.6)$ & $15(11.5)$ & $14(11.5)$ & $56(8.7)$ \\
\hline Outdoor (\%) & $7(4.3)$ & $5(2.2)$ & $10(7.6)$ & $4(3.3)$ & $26(4.0)$ \\
\hline Indoor (\%) & $5(3.1)$ & $10(4.4)$ & $5(3.8)$ & $10(8.2)$ & $30(4.7)$ \\
\hline Nursing/residential home (\%) & $6(3.7)$ & $20(8.8)$ & $12(9.2)$ & $11(9.0)$ & $49(7.6)$ \\
\hline In ambulance (\%) & $0(0.0)$ & $0(0.0)$ & $0(0.0)$ & $3(2.5)$ & $3(0.5)$ \\
\hline \multicolumn{6}{|c|}{ Previous medical history of cardiac disease } \\
\hline Documented (\%) & $135(82.8)$ & $153(67.7)$ & $119(90.8)$ & $84(68.9)$ & $491(76.5)$ \\
\hline Yes (\% documented) & $63(46.7)$ & $63(41.2)$ & $54(45.4)$ & $53(63.1)$ & $233(47.5)$ \\
\hline
\end{tabular}

NN, Northern Neighbourhoods; NWB, North and West Belfast.

scenario and skill retention assessed at 6-month intervals. Three hundred and thirty-five urban volunteers and 493 rural volunteers were trained in AED use.

The PAD schemes were introduced in year 2, 2005-6. The Northern Ireland Ambulance Service dispatch mechanism was based on the Advanced Medical Priority Dispatch System, (v11.1 Priority Dispatch Corp) ${ }^{11}$ coding and automated internet paging, facilitating automated "dual dispatch" of FRs, along with the EMS. Pager zones were constructed using digitised mapping software (Microsoft MapPoint, Europe, 2004) and population statistics, demographic information and spatial modelling techniques to minimise the response time of FRs to events and thus improve call to response intervals (CRI)s. There were three urban pager zones and three rural pager zones. FRs were only sent to calls which were coded as cardiac arrest by the Advanced Medical Priority Dispatch System. To be coded as such, the caller needed to report a collapse in which the patient was unconscious with absent or equivocal breathing. Implementation of the Advanced Medical Priority Dispatch System occurred in April 2005 in the rural area, resulting in an 11 -week delayed start of the PAD scheme in the rural area compared with the urban area. The PAD scheme thus ran for 63 weeks (17 January 2005-3 April 2006) in the urban area, and 52 weeks (4 April 2005-3 April 2006) in the rural area.

In total 82 mobile AEDs were placed throughout both study areas during year 2, (29 urban, 53 rural). Initially, there were seven FR AEDs in the urban area. For the final 3 months of year 2 the number of urban FR AEDs was doubled to 14. In the urban area there were 15 police mobile AEDs. In the rural area there were 24 FR AEDs and 19 deployed by the police. For the final 5 months of year 2, traffic police deployed an additional 10 mobile rural AEDs.

Table 2 Initial cardiac rhythms for out-of-hospital cardiac arrests (OHCAs)

\begin{tabular}{|c|c|c|c|c|c|}
\hline & NWB 2004 & NWB 2005-6 & NN 2004 & NN 2005-6 & Total \\
\hline All EMS-attended OHCAs (\%) & $158(96.9)$ & $216(95.6)$ & $121(92.4)$ & $114(93.4)$ & 609 (94.9) \\
\hline \multicolumn{6}{|c|}{ Initial rhythm (\% of EMS-attended OHCAs): } \\
\hline Ventricular fibrillation & $27(17.1)$ & $30(13.9)$ & $19(15.7)$ & $19(16.7)$ & $95(15.6)$ \\
\hline Asystole & $122(77.2)$ & $162(75.0)$ & $94(77.7)$ & $88(77.2)$ & $466(76.5)$ \\
\hline PEA & $9(5.7)$ & $24(11.1)$ & $8(6.6)$ & $7(6.1)$ & 48 (7.9) \\
\hline \multicolumn{6}{|c|}{ Bystander CPR performed (\% of EMS-attended OHCAs): } \\
\hline Yes & $41(25.9)$ & $57(26.4)$ & $50(41.3)$ & $44(38.6)$ & $192(31.5)$ \\
\hline Witnessed OHCAs only (\%) & $33(20.9)$ & $73(33.8)$ & $44(36.3)$ & $50(43.9)$ & $200(32.8)$ \\
\hline \multicolumn{6}{|c|}{ Initial rhythm (\% of witnessed events): } \\
\hline Ventricular fibrillation & $17(51.5)$ & $24(32.9)$ & $12(27.3)$ & $18(36.0)$ & $71(35.5)$ \\
\hline Asystole & $11(33.3)$ & $30(41.1)$ & $27(61.4)$ & $27(54.0)$ & $95(47.5)$ \\
\hline PEA & $5(15.2)$ & $19(26.0)$ & $5(11.4)$ & $5(10.0)$ & $34(17.0)$ \\
\hline
\end{tabular}

CPR, cardiopulmonary resuscitation; EMS, emergency medical services; NN, Northern Neighbourhoods; NWB, North and West Belfast; PEA, pulseless electrical activity. 
Table 3 Resuscitation and survival rates for emergency medical services (EMS)-attended out-of-hospital cardiac arrests (OHCAs)

\begin{tabular}{|c|c|c|c|c|}
\hline & NWB 2004 & NWB 2005-6 & NN 2004 & NN 2005-6 \\
\hline EMS-attended OHCAs & 158 & 216 & 121 & 114 \\
\hline Resuscitated, n (\%) & $11 / 158(7.0 \%)$ & $10 / 216(4.6 \%)$ & $8 / 121(6.6 \%)$ & $10 / 114$ \\
\hline Survived, n (\%) & $8 / 158(5.1 \%)$ & $3 / 216(1.4 \%)$ & $3 / 121(2.5 \%)$ & $4 / 114(3.5 \%$ \\
\hline Witnessed VF OHCAs & 17 & 24 & 12 & 18 \\
\hline Resuscitated, n (\%) & $10 / 17(58.8 \%)$ & $5 / 24(20.8 \%)$ & $6 / 12(50.0 \%)$ & $8 / 18(44.4 \%$ \\
\hline Survived, n (\%) & $7 / 17(41.2 \%)$ & $2 / 24(8.3 \%)$ & $2 / 12(16.7 \%)$ & $4 / 18(22.2 \%$ \\
\hline
\end{tabular}

NN, Northern Neighbourhoods; NWB, North and West Belfast; VF, ventricular fibrillation.

The AEDs used for the Northern Ireland Public Access Defibrillation (NIPAD) project were Samaritan S2 defibrillators (Heartsine Technologies, Belfast, UK). Each AED with a biphasic truncated exponential waveform delivered shocks of 100-150-200 J. ${ }^{12}$ The FR AEDs were kept with the designated "on-call" FR. The "on-call" FRs brought AEDs to arrests using their own private vehicles. At the end of a week "on-call", FRs returned the AEDs to their local hospital's emergency department for hand over to the next responder. Police AEDs were kept in police patrol vehicles. The EMS used manual defibrillators with a biphasic truncated exponential waveform.

In year 1 EMS vehicles were dispatched to possible OHCAs after an emergency call. In year 2 FRs (police and lay) were also alerted to possible OHCAs by long-range pagers and automated internet paging, thus facilitating dual dispatch with the EMS. The investigators compared CRIs for the EMS and FRs: in year 1 (EMS alone) and year 2 (EMS and FRs). The resuscitation (admission to hospital alive) and survival (discharge from hospital alive) rates were compared for years 1 and 2 .

\section{The emergency medical services}

The urban population is served by one doctor-led ambulance and two ambulance stations which house emergency paramedic-led ambulances. Each of the three rural local government districts have one ambulance station and the rural population is also served by two doctor-led ambulances based at two local hospitals.

\section{Ethics}

The study received ethics approval from the local research ethics committee, Queen's University, Belfast.

\section{Statistics}

The data collected were held in Microsoft Excel and SPSS data files. The $\chi^{2}$ test and Fisher's exact test were used to estimate the significance of differences in $2 \times 2$ and other contingency tables. The independent-samples $t$ test (one-sided) was used to test the statistical significance of the difference in means of response times.

\section{RESULTS}

\section{OHCA incidence}

Most OHCA incidents occurred in the home (83.2\%) and in men $(64.5 \%)$ across both localities and time periods (table 1$)$.

About half (47.5\%) of all OHCAs occurred in people with a previous history of cardiac disease. Fewer than one-third of OHCAs (32.8\%) were witnessed (table 2) and in $84.4 \%$ the initial rhythm was non-shockable (table 2 ). In only $15.6 \%$ was the initial rhythm VF.
Table 4 Call to response intervals

\begin{tabular}{llll}
\hline Region & $\begin{array}{l}\text { EMS (alone) } \\
\mathbf{2 0 0 4}\end{array}$ & $\begin{array}{l}\text { EMS (alone) } \\
\mathbf{2 0 0 5 - 6}\end{array}$ & $\begin{array}{l}\text { Best combined } \\
\text { FR/EMS 2005-6 }\end{array}$ \\
\hline NWB & & & \\
Mean & 7 min $0 \mathrm{~s}$ & $6 \min 3 \mathrm{~s}$ & $5 \mathrm{~min} 56 \mathrm{~s}$ \\
SD & $2 \operatorname{min~} 48 \mathrm{~s}$ & $3 \min 53 \mathrm{~s}$ & $3 \mathrm{~min} 53 \mathrm{~s}$ \\
Median & $7 \mathrm{~min}$ & $5 \mathrm{~min}$ & $5 \mathrm{~min}$
\end{tabular}

$\begin{array}{lccl}\text { NN } & & \\ \text { Mean } & 11 \min 2 \mathrm{~s} & 10 \min 9 \mathrm{~s} & 9 \min 22 \mathrm{~s} \\ \text { SD } & 6 \min 10 \mathrm{~s} & 5 \min 47 \mathrm{~s} & 5 \min 42 \mathrm{~s} \\ \text { Median } & 9 \min & 10 \min & 8 \min \end{array}$

EMS, emergency medical services; NN, Northern Neighbourhoods; NWB, North and West Belfast.

Table 3 shows the number of OHCAs that were successfully resuscitated and survived as a percentage of all EMS-attended OHCAs and all witnessed OHCAs with an initial rhythm of VF. There was no significant difference in the proportion resuscitated or surviving to leave hospital over the two time periods: for those surviving to leave hospital in the urban area (North and West Belfast (NWB)), 5.1\% and $1.4 \%$, and in the rural area (Northern Neigbourhoods (NN)), 2.5\% and 3.5\% for 2004, 2005-6, respectively.

There were 18 OHCA survivors from these two geographical regions (urban and rural) across the two observational time periods. Each survivor possessed at least two of the following three characteristics:

- their OHCA event was witnessed

- the initial rhythm was VF

- bystander CPR was performed.

Indeed 13 possessed all three characteristics. The initial rhythm was VF for 17 of the 18 survivors; 16 were witnessed events; and 16 received bystander CPR.

\section{PAD scheme}

The response times for the urban EMS were significantly better than for the rural EMS for each of the 2 years $(p<0.001$; table 4$)$. For the urban area (NWB), there was a significant improvement in the mean EMS CRIs between the two study periods, $7 \mathrm{~min}$ in 2004 , 6 min $3 \mathrm{~s}$ in 2005-6 ( $p=0.005$; table 4). For the rural area (NN), there was no significant improvement in the mean EMS response times between the study periods, mean CRI 11 min $2 \mathrm{~s}$ in 2004 and 10 min $9 \mathrm{~s}$ in 2005-6 ( $\mathrm{p}=0.131$; table 4).

In the urban area, FRs were paged to 128/226 (56.6\%) OHCA events, corresponding to $128 / 216$ (59.3\%) of all EMS-attended OHCA events. In the rural area, FRs were paged to $49 / 122$ (40.2\%) OHCA events, corresponding to $49 / 114$ (43.0\%) of all EMS-attended OHCA events (table 5).

The proportion of paged OHCAs reached by FRs before the EMS in the rural region was significantly higher than in the urban area: $23 / 49$ (46.9\%) versus 18/128 (14.1\%), $(p<0.001)$. For the 18 urban OHCAs where an FR arrived before the EMS, only $7 / 18$ (38.9\%) applied the AED. For the 23 rural OHCAs where an FR arrived before the EMS, only 10/23 (43.5\%) applied the AED. Of the total of 17 OHCAs in either area that had the AED applied only $2 / 17$ (11.8\%) had a shockable rhythm.

By combining the best FR response times with the best EMS response times (best combined FR/EMS) - that is, the shortest time to respond by any system to an OHCA event, we could analyse the impact of the FRs on EMS response to OHCAs (table 4, figs 1 and 2). For the urban area (NWB) the best combined FR/EMS CRIs in 2005-6, and the EMS CRIs in 2004 
Table 5 First responder (FR) contribution to out-of-hospital cardiac arrests (OHCAs)

\begin{tabular}{lll}
\hline Contribution & $\begin{array}{l}\text { NWB } \\
(\mathbf{n = 2 2 6})\end{array}$ & $\begin{array}{l}\text { NN } \\
\text { (n= 122) }\end{array}$ \\
\hline FRs were paged (n) & 128 & 49 \\
At least one FR attempted to respond, $\mathrm{n}(\%)$ & $88(68.8 \%)$ & $42(85.7 \%)$ \\
At least one FR arrived before the ambulance, $\mathrm{n}(\%)$ & $18(14.1 \%)$ & $23(46.9 \%)$ \\
\hline
\end{tabular}

NN, Northern Neighbourhoods; NWB, North and West Belfast.

were $5 \mathrm{~min} 56 \mathrm{~s}$ and $7 \mathrm{~min}$, respectively $(p=0.002)$. The urban FRs did not have any significant impact on the proportion of OHCAs reached within 8 min: 188/216 (87.0\%) versus 186/216 $(86.1 \%) \quad(p=0.888$; fig 1$)$. For the rural area (NN) the best combined FR/EMS CRI in 2005-6, and the EMS CRI in 2004 were $9 \min 22 \mathrm{~s}$ and $11 \min 2 \mathrm{~s}$, respectively $(p=0.018)$. The rural FRs did not have any significant impact on the proportion of OHCAs reached within 8 min: 57/114 (50.0\%) versus 51/114 $(44.7 \%)(p=0.507$; fig 2$)$.

\section{DISCUSSION}

The large-scale American ${ }^{13}$ and English $\mathrm{PAD}^{14}{ }^{15}$ schemes concentrated on placing AEDs in public places and community facilities. While the Italian study (Piacenza) included cardiac arrest in the home, with significant improvement in survival, ${ }^{16}$ there was no before-and-after analysis. Since the majority of arrests occur in the home the underlying logistics dictate the overall success of any PAD scheme. The NIPAD study attempted to examine all OHCAs including those in the home and was undertaken in both urban and rural communities. The poorer EMS response times which are inevitable in a rural setting mean that there may be a greater benefit from PAD in this setting.

In our study less than one-third of the OHCAs were witnessed and $<16 \%$ had a shockable rhythm when initially assessed. These factors contributed mainly to the poor survival rate. In addition, the small number of patients seen by the FRs before the EMS arrived did not contribute to the overall survival.

The EMS CRIs for Northern Ireland are comparable to those of other EMS systems. As expected, the mean urban EMS CRI, 6 min $3 \mathrm{~s}$, was significantly lower than the mean rural EMS CRI, 10 min $09 \mathrm{~s}(\mathrm{p}<0.001 ; 2005-6)$. Over $85 \%$ of urban EMS CRIs are better than the Department of Health target of 8 min, while only $45 \%$ of rural EMS CRIs reach the same target (figs 1 and 2). One alternative to PAD is enhancing existing EMS resources. However, it has been calculated that each second of improved EMS response time could cost as much as £28 000/ year. $^{17}$

We did show an improvement in mean CRIs reached by FRs in the rural area. The improvement in the urban area was primarily due to improvement in the EMS CRIs and not due to the PAD scheme. The NIPAD FRs did not achieve early defibrillation within 4 min. ${ }^{18}$ No community defibrillation scheme using mobile responders has achieved a mean call to response time of $<4$ min. Early defibrillation was achieved in the English national programme because the responders were "on-site" at the time of the arrests. ${ }^{15}$ While the English programme is very successful, ${ }^{15}$ the great majority of the arrests in the community remain unaddressed. Perhaps early defibrillation is an unachievable target, outside of specific environments such as public places, planes and casinos.

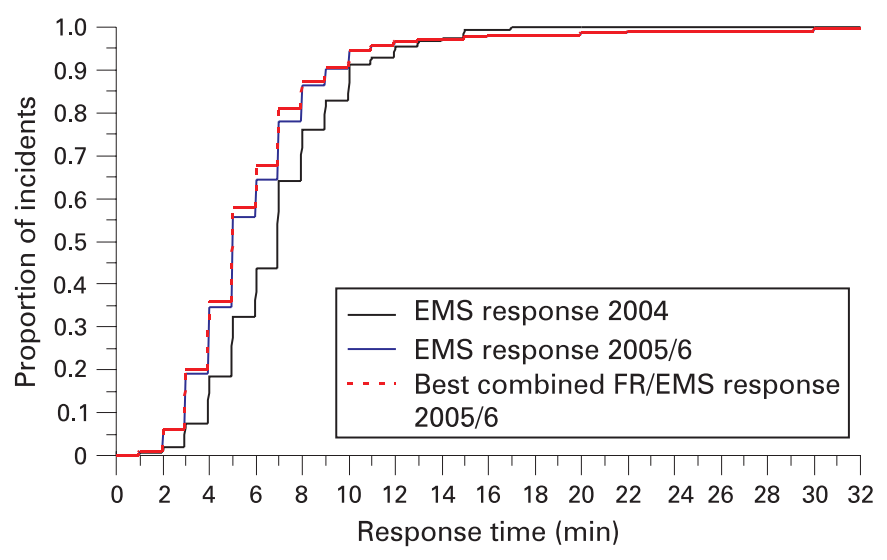

Figure 1 Call to response time distribution curves for North and West Belfast (NWB). Comparison of response times to emergency medical services (EMS)-attended out-of-hospital cardiac arrest events in NWB between 2004 and 2005-6, showing EMS alone and best combined first responder (FR)/EMS (cumulative response time distributions).

The AED pads application rate was poor for OHCAs reached first by FRs. Low AED application rate has been shown by other investigators. ${ }^{19} 20$ Reasons include apprehension; in other cases the EMS appeared to arrive almost immediately after the FR, especially in the urban area. Some volunteers assumed the collapsed victims to be "dead on arrival" despite instructions to the contrary. It is hoped that over time volunteers grow in both experience and confidence, leading to a higher success rate.

The lower incidence of VF as the presenting rhythm in the community, ${ }^{21}{ }^{22}$ the proportion of people living alone, ${ }^{23}$ public awareness or the ability to recognise sudden death and the sensitivity of EMS dispatch mechanisms all add to the low survival from OHCA. ${ }^{11}$

Patients with VF arrest have up to a 10-fold higher survival rate than patients with non-shockable rhythms. ${ }^{24}$ The potential survival rates which could be achieved given optimal conditions - that is, witnessed arrest with minimal delay in CRI, would depend on the proportion of patients in VF. In this study about $16 \%$ of the OHCAs had VF as the initial rhythm. Other investigators have reported the decline in VF among OHCAs. ${ }^{21} 22$ The Swedish cardiac arrest registry for OHCAs between 1991 and

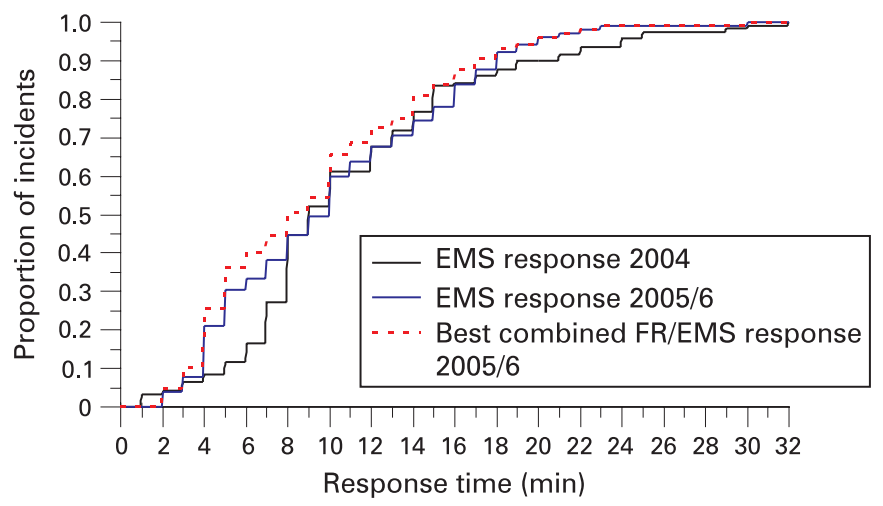

Figure 2 Call to response time distribution curves for Northern Neighbourhoods (NN). Comparison of response times to emergency medical services (EMS)-attended out-of-hospital cardiac arrest events in the NN between 2004 and 2005-6, showing EMS alone and best combined first responder (FR)/EMS (cumulative response time distributions). 
2001 has demonstrated that the proportion of patients in VF decreased from $45 \%$ to $28 \%$ over 11 years among those with witnessed arrest..$^{22}$ There are many hypotheses for this. Improved treatment of $\mathrm{CAD}$ with drugs and revascularisation means that more patients with $\mathrm{CAD}$ die from heart failure with nonshockable rhythms. Cobb et al observed a major decrease in the incidence of out-of-hospital VF in Seattle between 1980 and $2000 .{ }^{21}$ It was felt that these changes reflected the national decline in CAD mortality. We found no significant difference in the proportion of patients with VF between the urban and rural areas. With an a priori estimate of 160 OHCAs a year in each study area, ${ }^{25}$ a VF incidence of $15.6 \%$ suggests that an early defibrillation scheme has only the potential to save at most 25 OHCAs in each area. We demonstrated that the proportion of VF arrests was higher, at 35.5\%, among witnessed arrests but the small number of witnessed arrests in this study was a limiting factor in success.

Thirty nine per cent of people who die of OHCA in Northern Ireland live alone. ${ }^{23}$ This may explain the low proportion of witnessed arrests in the community. It is well recognised that unwitnessed OHCAs have minimal chance of survival. Delays in activation of the EMS play a role in prolonged response times and therefore the potential excess of non-shockable rhythms. Community schemes may be more effective if accompanied by a programme of public education. A factor that may dictate the survival benefits of any PAD scheme is the sensitivity of the dispatch mechanism. We have shown that the sensitivity of the dispatch mechanism was about $70 \%{ }^{11}$ and comparable to other systems. ${ }^{26}$ Widening the category of calls to which FRs are dispatched, to include all collapse calls, would improve the sensitivity of the dispatch mechanism and possibly CRIs but would be to the detriment of the scheme's specificity.

In the second half of year 2, the International Liaison Committee on Resuscitation (ILCOR) guidelines were updated. One of the new recommendations was for CPR to be delivered before defibrillation for out-of-hospital VF not witnessed by EMS personnel. ${ }^{27}$ At the time the NIPAD protocols were designed and for all of the duration of the FR training, the ILCOR resuscitation guidelines advised a defibrillation-first policy in all cases of VF arrest. ${ }^{28}$

The NIPAD study has many similarities with the Piacenza PAD study. ${ }^{16}$ Both studied an urban area with similar populations, both employed a mixed economy of responders, both used dual dispatch with the EMS, both had mobile AEDs and both concentrated on AED training. There were some differences, the NIPAD study investigated an urban and rural area, we employed a before-and-after study design, we used a new automated dispatch mechanism (the Piacenza investigators alerted responders by telephone calls) and about $60 \%$ of our responders also had CPR training.

The addition of CPR training to AED training is important. We have demonstrated that achieving early community defibrillation outside of niche environments is very difficult. In light of the recent updated resuscitation guidelines, ${ }^{27}$ this places an even greater emphasis on early and effective CPR in any community PAD scheme.

The Piacenza responders had a better mean response time than the urban NIPAD responders (4.8 $\mathrm{min}$ vs $5.9 \mathrm{~min}$ ) and therefore a greater number of responders reached events before the EMS (40.4\% in Piacenza, $14 \%$ in Belfast). The proportion of events presenting with a shockable rhythm was higher in Piacenza than Belfast (23.8\% vs $13.9 \%$ ), possibly owing to the shorter response times. The number of responders trained in Piacenza was a lot higher than in Belfast (1285 vs 335) for a similar population size.

\section{CONCLUSION}

Improving survival from OHCA is a considerable challenge and no one strategy is likely to constitute a single best approach. Systematic efforts to strengthen each link in the chain of survival would incrementally improve survival. Careful surveillance of all systems, including setting up robust, electronic cardiac arrest registries with adequate data collection in the field, would be essential.

Funding: The Research and Development Office, Investing for Health Grant. The Royal Victoria Hospital Fellowship. The British Heart Foundation.

\section{Competing interests: None.}

Ethics approval: Ethics approval obtained from the local research ethics committee, Queen's University, Belfast.

The NIPAD Study Steering Group comprised the investigators: Mr John Wright, Northern Ireland Ambulance Service; Inspector Yvonne Davidson, Police Service of Northern Ireland; Mr Peter Ferguson, research nurse, Queen's University, Belfast; Mrs Davina Gray, research nurse, Queen's University, Belfast; Ms Mary Black, N\&W Belfast Health Action Zone; Ms Hiliary Johnston, Investing for Health, Northern Ireland; Mr Stephen Murray, Investing for Health, Northern Ireland; Ms Florence Hand, HSS Northern Board.

\section{REFERENCES}

1. Norris RM. Fatality outside hospital from acute coronary events in three British health districts, 1994-5. BMJ 1998;316:1065-70.

2. Moore MJ, Glover BM, McCann CJ, et al. Demographic and temporal trends in out of hospital sudden cardiac death in Belfast. Heart 2006;92:311-5.

3. Nichol G, Stiell IG, Laupacis A, et al. A cumulative meta-analysis of the effectiveness of defibrillator-capable emergency medical services for victims of out-of-hospital cardiac arrest. Ann Emerg Med 1999;34:517-25.

4. Weaver WD, Peberdy MA. Defibrillators in public places - one step closer to home N Engl J Med 2002;347:1223-4.

5. Department of Health. Policy and guidance-ambulances. Available at http://www dh.gov.uk/en/Policyandguidance/Organisationpolicy/Emergencycare/ Modernisingemergencycare/DH_4063824 (accessed 9 August 2008).

6. Woollard M. Public access defibrillation: a shocking idea? J Public Health Med 2001;23:98-102.

7. Weisfeldt ML, Kerber RE, McGoldrick RP, et al. Public access defibrillation. A statement for healthcare professionals from the American Heart Association Task Force on Automatic External Defibrillation. Circulation 1995:92:2763.

8. Chugh SS, Jui J, Gunson K, et al. Current burden of sudden cardiac death: multiple source surveillance versus retrospective death certificate-based review in a large U.S. community. J Am Coll Cardiol 2004;44:1268-75.

9. Cummins R0, Chamberlain DA, Abramson NS, et al. Recommended guidelines for uniform reporting of data from out-of-hospital cardiac arrest: the Utstein Style. A statement for health professionals from a task force of the American Heart Association, the European Resuscitation Council, the Heart and Stroke Foundation of Canada, and the Australian Resuscitation Council. Circulation 1991;84:960-75.

10. Anonymous. Advanced cardiovascular life support. Part 4: The automated external defibrillator: key link in the chain of survival. Resuscitation 2000;46:73-91.

11. Cairns K, Hamilton AJ, Marshall AH, et al. The obstacles to maximising the impact of public access defibrillation: an assessment of the dispatch mechanism for out of hospital cardiac Arrest. Heart 2008;94:349-53.

12. Walsh SJ, McClelland AJJ, Owens CG, et al. Efficacy of distinct energy delivery protocols comparing two biphasic defibrillators for cardiac arrest. Am J Cardiol 2004;94:378-80.

13. Hallstrom A, Ornato JP. Public-access defibrillation and survival after out-of-hospital cardiac arrest. N Engl J Med 2004;351:637-46.

14. Davies CS, Colquhoun M, Graham S, et al. Defibrillators in public places: the introduction of a national scheme for public access defibrillation in England. Resuscitation 2002;52:13-21.

15. Davies CS. Colquhoun M, Boyle R, et al. A national programme for on-site defibrillation by lay people in selected high risk areas: initial results. Heart 2005;91:1299-302.

16. Capucci A, Aschieri D, Piepoli MF, et al. Tripling survival from sudden cardiac arrest via early defibrillation without traditional education in cardiopulmonary resuscitation. Circulation 2002;106:1065-70.

17. Fischer AJ, O'Halloran P, Littlejohns P, et al. Ambulance economics. J Public Health Med 2000;22:413-21.

18. Stotz M, Albrecht R, Zwicker G, et al. EMS defibrillation-first policy may not improve outcome in out-of-hospital cardiac arrest. Resuscitation 2003;58:277-82.

19. Lerner EB, Billittier AJ, Newman MM, et al. Automated external defibrillator (AED) utilization rates and reasons fire and police first responders did not apply AEDs. Prehosp Emerg Care 2002;6:378-82.

20. Mosseso VN Jr, Davis EA, Auble TE, et al. Use of automated external defibrillators by police officers for treatment of out-of-hospital cardiac arrest. Ann Emerg Med 1998; 32:200-7. 
21. Cobb LA, Fahrenbruch CE, Olsufka M, et al. Changing incidence of out-of-hospital ventricular fibrillation, 1980-2000. JAMA 2002;288:3008-13.

22. Herlitz J, Engdahl J, Svensson L, et al. Decrease in the occurrence of ventricular fibrillation as the initially observed arrhythmia after out-of-hospital cardiac arrest during 11 years in Sweden. Resuscitation 2004;60:283-90.

23. Hamilton AJ, Moore MJ, Cairns $\mathrm{K}$, et al. Risk factors in patients with an out-ofhospital cardiac arrest. Heart 2007;93(Suppl 1):A91, abstr 235.

24. Holmberg M, Holmberg S, Herlitz J. Incidence, duration and survival of ventricular fibrillation in out-of-hospital cardiac arrest patients in Sweden. Resuscitation 2000;44:7-17.
25. De Vreede-Swagemakers JJM, Gorgels APM, Dubois-Arbouw WI, et al. Out-ofhospital cardiac arrest in the 1990s: a population-based study in the Maastrich area on incidence, characteristics and survival. J Am Coll Cardiol 1997;30:1500-5.

26. Garza AG, Gratton MC, Chen JJ, et al. The accuracy of predicting cardiac arrest by emergency medical services dispatchers: the calling party effect. Acad Emerg Med 2003;10:955-60.

27. Anonymous. Part 5: Electrical therapies. Automated external defibrillators, defibrillation, cardioversion, and pacing. Circulation 2005;112:IV-35-46.

28. Anonymous. Emergency Cardiovascular Care Guidelines. Part 1: Introduction to the International Guidelines 2000 for CPR and ECC. A consensus on science Circulation 2000;102(Suppl I):1-384.

\section{WEB TOP 10}

www.heartjnl.com

These articles scored the most hits on Heart's website during September 2008

1 Low-dose CT coronary angiography in the step-and-shoot mode: diagnostic performance H Scheffel, H Alkadhi, S Leschka, A Plass, L Desbiolles, I Guber, T Krauss, J Gruenenfelder,

$M$ Genoni, T F Luescher, B Marincek, P Stolzmann

September 2008;94:1132-7. (Rapid Communication)

2 Treatment of atrial fibrillation

Y Blaauw, H J G M Crijns

October 2008;94:1342-9. (Education)

3 Cardiovascular, cerebrovascular, and respiratory changes induced by different types of music in musicians and non-musicians: the importance of silence

L Bernardi, C Porta, P Sleight

April 2006;92:445-52. (Original research)

4 Transposition of the great arteries: from fetus to adult

Jon Skinner, Tim Hornung, Elizabeth Rumball

September 2008;94:1227-35. (Education)

5 The universal definition of myocardial infarction: a consensus document

Joseph S Alpert, Kristian Thygesen, Allan Jaffe, Harvey $D$ White

October 2008;94:1335-41. (Education)

6 Alternatives to warfarin in atrial fibrillation: drugs and devices

Yves L Bayard, Stefan H Ostermayer, Horst Sievert

September 2008;94:1113-16. (Editorial)

7 JBS 2: Joint British Societies' guidelines on prevention of cardiovascular disease in clinical practice

December 2005;91(Suppl V):1-52. (Supplement)

8 Hypertrophic cardiomyopathy: lessons from history

C J Coats, A Hollman

October 2008;94:1258-63. (Review)

9 Impact on mortality following first acute myocardial infarction of distance between home and hospital: cohort study

L Wei, C C Lang, F M Sullivan, P Boyle, J Wang, S D Pringle, T M MacDonald

September 2008;94:1141-6. (Original article)

10 Prevalence of exercise-induced left ventricular outflow tract obstruction in symptomatic patients with non-obstructive hypertrophic cardiomyopathy

J S Shah, M T T Esteban, $R$ Thaman, $R$ Sharma, B Mist, A Pantazis, D Ward, S K Kohli, S P Page,

C Demetrescu, E Sevdalis, A Keren, D Pellerin, W J McKenna, $P$ M Elliott

October 2008;94:1288-94. (Original article)

Visit the Heart website for hyperlinks to these articles, by clicking on "Top 10 papers"

www.heartjnl.com 